\title{
Conversación en La Catedral desde el criterio ético del bildungsroman ${ }^{1}$
}

Conversación en La Catedral and the ethical criteria of the Bildungsroman

Vanessa Vera Chaparro²

Universidad Científica del Sur. Lima, Perú

vverac@cientifica.edu.pe

ORCID 0000-0002-7511-4112

Citar como: Vera Chaparro, V. (2019). Conversación en La Catedral desde el criterio ético del Bildungsroman. Desde el Sur, 11(2), pp. 227-237.

\section{RESUMEN}

En el marco del cumplimiento de los 50 años de la aparición de Conversación en La Catedral (1969), este artículo plantea una lectura estructural usando como referente el planteamiento de la teórica del bildungsroman María de los Ángeles Rodríguez Fontela (1996). Asimismo, mediante el concepto de ética, propuesto por Alain Badiou, analiza el proceso formativo de Santiago Zavala, para lo cual se parte de su desempeño político y de la relación que establece con su padre.

\section{PALABRAS CLAVE}

Santiago Zavala, bildungsroman, ética, política, relaciones filiales

\section{ABSTRACT}

Within the context of the fiftieth anniversary of the publication of Conversación en La Catedral (1969), this article proposes a structural reading of the novel based upon the work of the Bildungsroman theorist María de los Ángeles

1 Este artículo forma parte de la tesis de maestría desarrollada para optar el grado de magíster en Literatura Peruana y Latinoamericana de la Universidad Nacional Mayor de San Marcos.

2 Egresada de la maestría en Literatura Peruana y Latinoamericana de la Universidad Nacional Mayor de San Marcos y licenciada en Literatura por la Universidad Nacional Federico Villarreal (UNFV). Ha publicado artículos en revistas especializadas y ha presentado ponencias sobre la novela peruana del siglo XX en el Perú, Brasil y Bolivia. Es docente de la Facultad de Humanidades de la UNFV. 
Rodríguez Fontela (1996). At the same time, with reference to the ethical concepts discussed by Alain Badiou, we seek to analyze the formative process of Santiago Zavala, addressing both his political development and his relationship with his father.

\section{KEYWORDS}

Santiago Zavala, Bildungsroman, ethics, politics, filial relations

\section{Introducción}

El bildungsroman es un subgénero novelístico que apareció en la Alemania del siglo XVIII. A pesar de la existencia de un sector crítico tradicionalista que defiende su naturaleza exclusivamente alemana, su influencia y repercusión se ha extendido a diversos espacios que han trascendido incluso Europa. Llama nuestra atención que varias novelas peruanas como Crónica de San Gabriel (1960), La ciudad y los perros (1963), El viejo saurio se retira (1969), Los verdes años del billar (1986), Ximena de dos caminos (1998), País de Jauja (1993), entre otras, hayan recurrido a las fórmulas de este subgénero. En ese sentido, Conversación en La Catedral no ha sido la excepción. Esto, como es de esperarse, ya había sido advertido por algunos críticos como Román Soto (1990) y Edmundo Bendezú (1992), cuyos estudios abordaremos en el siguiente acápite.

Por otro lado, se ha discurrido constantemente sobre el carácter moral de las acciones que ejecuta Santiago Zavala. Por ejemplo, Peter Elmore (1993) sostiene: «El desclasamiento de Santiago —o, si se prefiere, su descenso es estatus - es claramente una opción moral, una forma de resistencia privada, como él mismo se encarga de subrayar» (p. 193). Aparentemente, al apartarse de su clase social de origen, Santiago actúa moralmente. Su fallida incorporación al Partido Comunista se transforma en un reclamo desde la individualidad, lo cual, evidentemente, en poco o nada desestabiliza el orden imperante; incluso podría resultar contraproducente, en tanto contribuye al sostenimiento de los grupos de poder corruptos. El desclasamiento, entendido como el distanciamiento de su familia, y la negación a disfrutar de sus privilegios de clase no llevan a Santiago a ninguna participación social. Desde su enclaustramiento, por el contrario, emprende dos acciones con las cuales traiciona nuevamente su pensar y que analizaremos en el tercer acápite: la revinculación con su padre luego del asesinato de la musa y la que también establece con Ambrosio para acceder a su verdad. 


\section{Antecedentes}

Edmundo Bendezú (1992) plantea que la novela de Vargas Llosa desarrolla tres otras novelas a la vez, cuyo eje común y transversal es «la educación de tres peruanos a mediados del siglo XX» (p. 298): Cayo Bermúdez, Ambrosio Pardo y Santiago Zavala. Esta afirmación es, para nosotros, incluso más certera si consideramos que el proceso educativo de cada uno de los mencionados personajes coinciden, asimismo, en establecer un conflicto con la generación anterior. Los tres son simbólicamente huérfanos de padre y no alcanzan una relación armoniosa con la figura paternal. Además de ello, los padres de esta novela no cumplen con el rol de guías en la formación de sus vástagos y, por el contrario, contribuyen al fracaso de sus proyectos de vida ${ }^{3}$. En este sentido, y retornando al planteamiento de Bendezú, cabría destacar la alegoría que surge de esas historias: el componente educativo que se repite representa un emblema del país en desarrollo. Pero no solamente es en este plano en el que se alegoriza al Perú, también lo es en términos políticos, incluso más si nos concentramos en el desempeño y evolución de Santiago.

Como es sabido, el bildungsroman suele presentar un final abierto, en el sentido de que la historia del héroe no parece concluir $y$, por el contrario, deja indicios para que el lector imagine fácilmente la aparición de una segunda parte de la novela. Así sucedió con Los años de aprendizaje de Wilhelm Meister, a la que le siguió Los años itinerantes. Román Soto (1990), por su parte, ha ubicado a Conversación en La Catedral en este segundo momento ${ }^{4}$, debido a que la considera una novela de confrontación, término obtenido de las investigaciones de Susan Suleiman (1983), quien caracteriza así al encuentro abrupto entre, por un lado, los valores aprendidos y asumidos por el héroe $y$, por otro, los opuestos, representados por su adversario. Se crea, por tanto, una tensión entre el héroe y su entorno.

La paradoja radica en que Santiago abandona su actitud beligerante frente al mundo tan pronto la ha iniciado:

Así como en La ciudad y los perros la ausencia de una comunicación feliz y la inamovilidad del mundo imposibilitan el aprendizaje

\footnotetext{
3 Cayo culmina su historia con su instalación en una mansión, en la que conserva su opulenta condición económica. Sin embargo, previo a ello se ha gestado su exclusión del poder y el fracaso de la proyección de su rol como gobernante.

4 Con esta afirmación, la lectura de Soto sugiere que Conversación en La Catedral es una continuación de La ciudad y los perros. Pero si tuviéramos que ubicar una continuación del desarrollo del protagonista, creemos que más bien esta es posible identificarla en Kathie y el hipopótamo (1983), que, aunque es una pieza teatral, presenta no solo a un frustrado Santiago, sino también a Ana, quienes experimentan un fracasado matrimonio. Entre la novela del 69 y esta obra de teatro hay varios elementos que se repiten como el desprecio por la burguesía, el trabajo de Santiago en La Crónica o la ideología comunista.
} 
positivo del héroe, en Conversación en La Catedral expulsan todo deseo de saber y conducen a un rápido abandono de una confrontación apenas iniciada obliterando la acción (resaltado agregado) (Soto, 1990, p. 70).

Con esta afirmación, Soto continúa la línea de los críticos que afirman que Santiago ha sido malogrado por las circunstancias externas que enmarcan su desarrollo. Sigue siendo la víctima, lo cual siempre será una condición que le reste, e incluso anule, toda injerencia sobre su entorno. Alain Badiou (2004) ha advertido ya este problema de la «ética de los derechos humanos», que, en una desastrosa paradoja, define al hombre como «bestia sufriente» o «moribundo descarnado» (p. 35): «En tanto que verdugo, el hombre es una abyección animal, pero es preciso tener el valor de decir que en tanto víctima, en general no es mucho mejor» ( $p$. 35). Posteriormente, Badiou (2004) es todavía más contundente: «Si los verdugos y burócratas de los calabozos y de los campos pueden tratar a sus víctimas como animales destinados al matadero [...], es porque las víctimas se han transformado realmente en animales» (p. 37). Por tanto, sujetarse a las inevitables consecuencias de la dictadura odriista y no mostrar ningún afán de ser algo distinto a una víctima convierten a Santiago en un «ser-para-la-muerte» (p. 36). El mérito habría estado en «persistir en ser lo que es; es decir, precisamente otra cosa que una víctima» (p. 37). La apatía que caracteriza la actitud de Santiago lo conduce al sufrimiento y a ser un hombre para la compasión, la misma que por él siente la Teté, el Chispas, su madre o, lo que es peor, él mismo, pues es fácil identificar cómo Santiago se ha autonegado toda posible perspectiva positiva de su condición. De ahí que su pregunta para indagar sobre el momento en que se jodió parta de un a priori que da por sentada su condición y anula una búsqueda de solución.

\section{Santiago Zavala y la naturaleza ética de su proceso formativo}

Rodríguez Fontela (1996) propone que en el bildungsroman prima la búsqueda del yo, es decir, el recorrido que realiza el protagonista es para hallarse: «Su especificación temática la vincula, en efecto, a las experiencias de transformación y madurez humanas, al tránsito de la inocencia al estado adulto, a la búsqueda permanente de la identidad personal» (p. 467). Lo mismo es posible observar en Conversación en La Catedral. Santiago plantea una interrogante bien conocida: «¿En qué momento se había jodido el Perú?», a lo que es importante también adicionar su propia duda: «Yo daría cualquier cosa por saber en qué momento me jodí». Y ensayará una serie de respuestas con las que buscará determinar si se jodió en San Marcos, en La Crónica, al conocer a Jacobo y Aída, o en otra circunstancia. Los personajes en búsqueda constante son precisamente característicos del 
bildungsroman, lo cual se materializa en esta novela mediante esa pregunta que persiste. Por eso, es posible reconocer en su proceso formativo un constante deseo de definición, es como una investigación del yo, una que se asemeja a la que un detective ejecuta para resolver un enigma, como lo es un asesinato. Asimismo, la transición del Perú al yo es una clara muestra de cómo la interrogante nacional termina recalando en una individualidad. Esta mismidad evidencia que Santiago solo busca resolver su conflicto íntimo, lo cual se refuerza nuevamente cuando indagamos en las razones por las que él invita a Ambrosio a una conversación en la que solo pretende resolver sus dudas sobre su padre Fermín, para, de esta manera, medir la repercusión que esta revelación tendrá en su individualidad.

Además, Rodríguez Fontela (1996) prefiere traducir el término bildungsroman a «novela de autoformación» y asocia su origen con la iniciación tribal, es decir, con los ritos de iniciación de los adolescentes de las comunidades nativas. Resume estos eventos mediante tres momentos: el retiro del adolescente de la comunidad, el sometimiento de pruebas bajo la supervisión de los maestros y la incorporación al mundo adulto como «hombre acto»: «El eje estructural de la novela de formación es la construcción de una personalidad que ha de superar, en el transcurso de la narración, un proceso iniciático» (Rodríguez Fontela, 1996, p. 63).

Ese primer momento del distanciamiento queda representado en Conversación en La Catedral cuando Santiago experimenta una aparente ruptura filiativa con el orden paternal. Esta es la etapa del desarrollo del personaje propia del mencionado subgénero: la renuncia al pensamiento heredado por nacimiento. Esta distancia presente en las novelas de formación no es solo física, sino también ideológica, ya que es el medio por el cual el protagonista puede alcanzar su propia perspectiva, y así precisamente se inicia la separación de Santiago. En esta búsqueda de una identidad ideológica propia, Santiago se encontrará con su faceta política. Este es precisamente uno de los elementos que le confieren particularidad al bildungsroman latinoamericano, ya que muchos de sus personajes pertenecen a la clase media, situación socioeconómica tan problemática como su mismo nombre lo indica, dado que sus individuos experimentan dudas e incertidumbres que no están presentes en las clases altas o en las populares. Habría que precisar que esa separación de Santiago queda ya iniciada antes de la fuga que emprende para instalarse en una pensión, puesto que ya demostraba pensamientos opuestos a los de su familia. Estas diferencias se visualizan en el modo en que la Teté y el Chispas se refieren a él con términos como «supersabio» o «mula chúcara».

La relación de Santiago con la poesía es corta e incomprendida por su entorno. El rechazo de sus hermanos se evidencia en sus burlas sobre 
los poemas que escribe Santiago, lo que el Chispas aprovecha para mofarse de él usando términos peyorativos con los que pretende disminuir su masculinidad. A propósito de esto, en «El poder de la memoria» (1987), siguiendo la distinción de Karl Popper entre sociedades abiertas y cerradas, Vargas Llosa sostiene: «En las sociedades cerradas el poder no sólo se arroga el privilegio de controlar las acciones de los hombres - lo que hacen y lo que dicen-; aspira también a gobernar su fantasía, sus sueños y, por supuesto, su memoria» (p. 55). Al configurar un Perú gobernado por la dictadura, Vargas Llosa ha ensayado en la diégesis de su novela una sociedad cerrada, en la que Santiago abandona sus deseos de ser poeta y en la que Carlitos no retorna más a los poemas que confiesa escribir; no existe, por tanto, espacio para la literatura. Esta vez no ha sido la salvación de nadie. Es más, ni el cuadro memorioso que Santiago le exige elaborar a Ambrosio le podrá otorgar su liberación. En estas sociedades, el hombre se ha reducido a su condición de especie viviente, acepta «ser-un-animal al que la circunstancia lo expone» (Badiou, 2004, p. 37). Lo extraño es que el héroe de esta novela parece regocijarse en su condición de animal sufriente y cree ver en esto una actitud heroica: «Y en este país el que no se jode, jode a los demás. No me arrepiento, Ambrosio» (p. 166).

La iniciación, que también puede darse «a una clase, a una edad, a un estado, a una sociedad, [a una ideología, a una militancia]» (Rodríguez Fontela, 1996, p. 64), se expresa con diversos momentos de la novela, pero siempre culminan desastrosamente. Cuando Santiago ingresa a San Marcos, conoce a Aída y a Jacobo, al lado de quienes experimenta sus primeros encuentros con el comunismo. Posteriormente, este interés se organiza y ya se puede observar un grupo más amplio conformado por el cholo Martínez, Llaque, Washington y Héctor. A ello se suma un evento bastante significativo que consiste en recibir un seudónimo: Julián. El truncamiento de esta iniciación se empieza a evidenciar cuando Santiago confiesa que constantemente se le olvida la responsabilidad que le asignaron e, incluso, no se siente interpelado cuando lo llaman Julián. Anniken Iversen (2009) ha destacado la importancia de la búsqueda de nuevos compromisos con personas e ideas en el bildungsroman. En el caso de Santiago, este objetivo se va desdibujando cuando lo observamos cancelar todo vínculo con la fracción.

Por tanto, la performance política de Santiago no prospera, pero lo paradójico es que esto sucede por su entera responsabilidad, ya que él y sus compañeros son capturados, debido a que Cayo Bermúdez tenía intervenidos los teléfonos de su casa. En este momento, esa distancia establecida con su padre se acorta velozmente, pues gracias a los contactos de don Fermín con el poder de Odría, logra su libertad. Luego de 
una fuerte discusión con su padre es cuando recién decide establecer el distanciamiento espacial, pero que, paradójicamente, ya no es ideológico, dado que en ese momento también decide alejarse de la política y del comunismo. Al parecer, se reconoce impotente para asumir el rol de un sujeto político fiel a una utopía; tampoco comprende bien por qué se debe asumir ese rol.

La huida de casa lo lleva a frecuentar a personas vinculadas con el periodismo gracias a la intervención de su tío Clodomiro. En este nuevo ambiente, conoce a Carlitos y a Becerrita, quienes le irán mostrando los secretos de una profesión que se opone a su extinta vocación artística. Al mismo tiempo, lo van a introducir en espacios de la urbe periférica como los bares y prostíbulos. El periodismo servirá como guía para un Santiago que anhela librarse de la dependencia paternal, pero también será el medio eficaz que, antes de tiempo, le permita acceder a la epifanía: la real dimensión de su padre don Fermín, quien mantiene una relación homosexual con su chofer y también es el asesino intelectual de la Musa. No obstante, y a pesar de darse de cara a la verdad, Santiago huye de esta revelación y, años más tarde, ya muerto su padre, aún sin aceptar la verdad, anhela que sea Ambrosio quien se la muestre, pretende convertir al antiguo chofer de su familia en el mediador de una revelación a la que ya tuvo acceso, pero que en vez de dejarse interpelar por ella, optó por ser cómplice de su ocultamiento. Es así como decide revincularse con su padre luego de varios años de distanciamiento para advertirle que su nombre se encuentra circulando en el inframundo limeño, bajo el seudónimo de Bola de Oro:

—Yo quería que supieras, papá — dijo Santiago-. Si los periodistas y la policía se ponen a averiguar, a lo mejor van a molestarte a la casa. -Muy bien hecho, flaco - asentía, Zavalita, sonreía, tomaba sorbitos de café-. Hay alguien que quiere fregarme la paciencia (resaltado agregado) (vol. II, p. 44).

El hábitus burgués de Santiago continúa inquieto durante unos días más. Esto significa que la distancia física impuesta por él mismo en relación con su familia, al irse de su casa, no es más que eso, un movimiento espacial, un desplazamiento corporal, pues la revinculación con su padre se expresa fuertemente en sus preocupaciones e inquietudes:

—Pero lo otro no puede ser cierto, Carlitos — dijo Santiago-. Lo otro tiene que ser una calumnia. Eso no puede ser, Carlitos.

[...]

—Tú conoces a Becerrita — dijo Santiago—. No está enterrada. Tú sabes lo que va a hacer. 
- Consultar con Arispe y Arispe con el Directorio, claro que sé - dijo Carlitos-. ¿Crees que Becerrita es cojudo, que Arispe es cojudo? La gente bien no aparece nunca en la página policial. ¿Te preocupaba eso, el escándalo? Sigues siendo un burgués, Zavalita (vol. II, pp. 37-38).

De manera truculenta, Santiago es partícipe de las redes corruptas del poder. Aunque haya declarado que usa el periodismo para, indirectamente, provocar rechazo en algún joven y despertar su conciencia crítica, en otra escena se ve involucrado con el caso Bola de Oro y le designan, con cínica complicidad, la labor de crear una noticia para eludir la verdad acerca de la implicancia de Fermín Zavala en el caso que lo acusa de homosexual y lo involucra con la muerte de la Musa:

-No hay nada nuevo, fuera de las cojudeces de esa puta, mejor nos olvidamos - gruñó Becerrita, revolviendo con desesperación unos papeles-. Hágase una carilla de relleno, Zavalita. Prosigue la investigación, se examina nuevas pistas. Cualquier cosa, una carilla. (vol. Il, p. 48).

Si analizamos también la pretendida etapa de distanciamiento ideológico de Santiago, necesaria en el bildungsroman, es fácil identificar que, en su acercamiento al círculo comunista, no logra ser fiel a la idea que sus integrantes propugnan. Su mirada crítica le hace advertir las falencias y debilidades de Cahuide, con lo que nuevamente cae en un vacío; atribuye, otra vez, su «falta de fe» a circunstancias externas y queda sin propuestas autovalidadas que impidan su caída. Realmente, Santiago no logra apartarse del grupo social que su padre representa, tampoco es el paradigma de los que rechazan y se sustraen a las relaciones de poder, sino que termina siendo absorbido por este.

Como sabemos, Edward Said (2004) explica que, luego de la voluntaria anulación de la filiación, los nuevos lazos de afiliación emergen como una nueva forma de comunidad ante la imposibilidad de mantener los lazos filiativos: relaciones familiares basadas en una autoridad biológica. La ruptura con el patrón filial requiere una posición crítica consciente que suele aparecer durante la adolescencia. Tal como se ha ejemplificado en los recientes fragmentos citados de la novela, Santiago retorna constantemente a esa autoridad representada por su padre. Por ende, el distanciamiento crítico no tiene éxito en su formación.

Ambos momentos son cruciales en el desarrollo de este personaje, pues su rechazo a la verdad es el que lo conduce a la crisis. Cuando Ambrosio le pregunta qué quiere, este responde: "Que dejes de hacerte el cojudo [...]. Que hablemos con franqueza de la musa, de mi papá» (Vargas Llosa, 1969, vol. I, p. 29). Recordemos que el fin supremo de todo 
bildungsroman es el autoconocimiento propiciado por el acceso del héroe a la verdad, de ahí que muchas de estas novelas utilicen la trama de la novela policial. Pero si este se rehúsa a asimilarla, su proceso de pruebas corre el riesgo de no culminar con éxito.

También es posible identificar otros intentos fallidos de los rituales de iniciación en el desarrollo de Santiago. Por ejemplo, busca su iniciación sexual y en esta es guiado, con notorio desacierto, por su hermano mayor: «No te muñequees, dijo el Chispas, ¿tienes hembrita?, Santiago le mintió que sí y el Chispas, preocupado: es hora de que te desvirgues, flaco, de veras» (vol. l, p. 39). Santiago deberá demostrar que es un hombre mediante su primera relación sexual. Urde un plan junto a Popeye que consiste en darle una droga a Amalia para que sea ella quien le brinde ese ansiado pase a la demostración de su masculinidad. Su plan, además de ser interrumpido por la llegada de sus padres, muestra que no logra lo estipulado por su hermano: «los hombres se ganan su polvo a pulso» (vol. l, p. 39). Santiago, como vemos, tiende a crear simulacros de guías o maestros, puesto que ninguno logra representar dicho papel cabalmente. Esto es una consecuencia de la falsa ruptura filiativa con la figura paternal, y, a su vez, es razón para demostrar que la educación de Santiago, en vez de formarlo, lo deforma, y él no logra identificar alternativas a las que asirse.

El ritual, como ya mencionamos, debe culminar con la reincorporación al lugar de origen. Sin embargo, Santiago no lo hace. Esto es evidente en la novela, pero también, como ya hemos visto, puede notarse que ni siquiera a nivel de espacio físico esta ruptura existe en realidad, porque la Quinta de los Duendes en donde termina instalado con su esposa se ubica en Miraflores, lugar en el que también vive su familia. Así y aunque haya decidido rechazar la herencia paternal, Santiago, en realidad, no ha logrado una verdadera ruptura, solo ha optado por recluirse en un espacio indefinido. Si en el prototipo de Los años de aprendizaje de Wilhelm Meister el protagonista se entera de que Mariana tuvo un hijo suyo y decide darle una familia a este niño, además de regresar a su ciudad natal para establecer su nueva familia, ahora al lado de Natalia, joven virtuosa que interviene metafóricamente en una escena en que pone en brazos de Wilhelm a su hijo, por su parte, Santiago no logra establecer una familia en el sentido que exige la sociedad, pues, a modo de caricatura, él y su esposa Ana tienen un perro en vez de un hijo. Pareciera que con esto se confirma que Santiago no puede rehacer sus propios lazos filiativos si no ha logrado deshacer los que lo unen a la familia Zavala.

Ya nada, en su presente, le proporciona satisfacción, ni siquiera su intento de mantenerse alejado de la corrupción burguesa le brinda estabilidad ideológica. Él se instala de manera física en una clase social no tan 
distinta a la que recibió por herencia, casado con una enfermera, habitando una quinta miraflorina, habiéndose negado la posibilidad de disfrutar una herencia, pero desempeñándose en un trabajo que refuerza el poder. En suma, un desplazamiento figurativo que no llega a concretar una compatibilidad con la clase de llegada, un proceso de formación que no se condice con las primeras pautas que él mismo se impuso. Habría que pensar entonces en un bildungsroman en el que el éxito de la reconciliación yo-mundo sea solo una quimera, una ilusión imposible en un clima dictatorial, pero imposible, sobre todo, por la ausencia del valor y esfuerzo de abrazar una ideología nueva.

\section{Contribuciones}

Vanessa Vera Chaparro ha participado en la concepción del artículo, la recolección de datos, su redacción y aprobación de la versión final.

\section{Fuente de financiamiento}

Autofinanciado.

\section{Conflicto de interés}

El autor declara no tener conflictos de interés 


\section{REFERENCIAS BIBLIOGRÁFICAS}

Badiou, A. (2004). La ética. Ciudad de México: Herder.

Bendezú Aibar, E. (1992). La novela peruana. De Olavide a Bryce. Lima: Editorial Lumen.

Elmore, P. (1993). Los muros invisibles: Lima y la modernidad en la novela del siglo XX. Lima: Mosca Azul Editores y El Caballo Rojo.

Iversen, A. (2009). Change and Continuity: The Bildungsroman in English. Tromsø: University of Tromsø.

Rodríguez, M. de los Á. (1996). La novela de autoformación: una aproximación teórica e histórica al «Bildungsroman» desde la narrativa hispánica. Kassel: Reichenberger y Universidad de Oviedo.

Said, E. (2004). El mundo, el texto y el crítico. Buenos Aires: Debate.

Soto, R. (noviembre, 1990). Fracaso y desengaño: Héroes, aprendizaje y confrontación en La ciudad y los perros y Conversación en La Catedral. Chasqui, (19)2, pp. 67-74.

Vargas Llosa, M. (1969). Conversación en La Catedral (2.a ed.). vol. I y II. Barcelona: Seix Barral. 